\title{
Reviewing estimates of the economic efficiency of disaster risk management: opportunities and limitations of using risk-based cost-benefit analysis
}

\author{
R. Mechler ${ }^{1}$
}

Received: 8 April 2015/ Accepted: 14 January 2016/Published online: 5 February 2016

(C) The Author(s) 2016. This article is published with open access at Springerlink.com

\begin{abstract}
There is a lot of rhetoric suggesting that disaster risk reduction (DRR) pays, yet surprisingly little in the way of hard facts. This review paper examines the evidence regarding the economic efficiency of DRM based on CBA. Specifically, it addresses the following questions: What can be said about current and best practice regarding CBA for DRR including limitations and alternatives? And, what, if at all, can be said in terms of quantitative insight for informing policy and practice? The review compares the documented evidence on the net benefits over a range of disaster management interventions, such as risk reduction, preparedness and risk financing. The review also critically discusses the applicability of cost-benefit analysis as well as other economic decision-supporting tools for assessing the efficiency of certain DRM interventions. Disaster risk is characterized by variability, which requires a risk-based assessment. As a key best practice criterion, and in order to avoid overestimating the benefits and returns on investment, the review focuses on studies that provide a risk-based estimate of benefits. This review shows that for the limited evidence reported the economic case for DRM across a range of hazards is strong and that the benefits of investing in DRM outweigh the costs of doing so on average, by about four times the cost in terms of avoided and reduced losses. In an age of austerity, cost-benefit analysis continues to be an important tool for prioritizing efficient DRM measures but with a shifting emphasis from infrastructure-based options (hard resilience) to preparedness and systemic interventions (soft resilience), other tools such as cost-effectiveness analysis, multi-criteria analysis and robust decision-making approaches deserve more attention.
\end{abstract}

Keywords Cost-benefit analysis - Disaster risk management - Appraisal · Economic efficiency $\cdot$ Multi-criteria analysis

Electronic supplementary material The online version of this article (doi:10.1007/s11069-016-2170-y) contains supplementary material, which is available to authorized users.

R. Mechler

mechler@iiasa.ac.at

1 International Institute for Applied, Laxenburg, Austria 


\section{Introduction: the costs and benefits of disaster risk reduction and the role of risk}

The World Conference on Disaster Risk Reduction in Sendai, Japan, in early 2015 corroborated the strong interest by policymakers, disaster practitioners and analysts regarding the need for prioritizing predisaster risk reduction in lieu of the predominant focus on postdisaster provision of relief and reconstruction assistance. As one of four priority areas for action over the next 15 years, this conference identified "Investing in disaster risk reduction for resilience" (UN 2105). Although there has been substantial progress in upgrading investment into ex-ante risk reduction over the last few years, still, there is, arguably, a serious bias towards reliance on ex-post response rather than ex-ante risk reduction. Many reasons can be brought forward to explain this bias, and at least one factor is limited evidence regarding the benefits of risk reduction. Cost-benefit analysis (CBA) is a key analytical tool that can provide quantitative information regarding the prioritization of risk reduction based on comparing benefits of an actual or planned intervention with its costs. Applying CBA to disaster risk reduction (DRR) is nothing new, and the economic efficiency criterion has been an important concern for many policymakers including donors, NGOs and international financial institutions investing in DRR. CBA has been applied to the assessment of DRR, yet, in contrast to rhetoric suggesting the potentially large benefits of DRR, sparsely so, and with remaining deficiencies, an important one being the lack of taking a truly risk-based approach. What is more, there has been relatively little reflection regarding the potential and usefulness of CBA for this problem domain.

Moench et al. (2007) review the literature and find positive return to many studies assessed. They categorize interventions into hard and soft type of measures. Hard resilience refers to the strengthening of structures and physical components of systems in order to brace against shocks imposed by extremes such as earthquakes, storms and floods. In contrast, soft resilience refers to less tangible and process-oriented measures as well as policy in order to robustly cope with events as they occur and minimize the adverse outcomes. Hawley et al. (2012) summarize a number of CBA studies focussed on flood risk reduction. The authors classify results by the type of risk reduction strategy into three main categories: (1) structural and non-structural-levees, dams, diversions and channel improvements, flood gates, restoration of floodplain, detention basins; (2) exposure and property modification-zoning and land-use planning, voluntary purchase, building codes and regulation, house elevation, other flood proofing; and (3) behavioural-information and education, preparedness, forecasts and warning systems, emergency response. The review finds that many of the highest economic returns exist for behavioural DRR strategies as well as restoration of floodplains and flood proofing. Shreve and Kelman (2014) in a recent comprehensive review on CBA case studies cutting across different geographies, hazard types and vulnerabilities find solid evidence for the "business case for DRR". The authors also identify important shortcomings, such as a lack of sensitivity testing of results, gaps regarding the inclusion of climate change, lack of consideration of disbenefits and representations of vulnerability; yet, the review does not consider the role of probability and risk.

As a key gap, these reviews did not consider (Hawley et al. 2012; Shreve and Kelman 2014) or only give some credit (Moench et al. 2007) to the role of risk in CBAs. As disaster risk is characterized by low-probability, high-impact events, truly considering risk and capturing variability probabilistically is a very important design and assessment characteristic. Ideally, such risk assessment requires probabilistic analysis to adequately represent 
the potential for impacts as well as the benefits in terms of reduced impacts. If risk is not taken care of by properly distinguishing, between events with a recurrency of 10, say, 20-, 50- and 100-year events (which are associated with annual probabilities of 10, 5, 2 and $1 \%$, respectively), essentially the analysis conducted is deterministic and the benefits considered (risk avoided) automatically have a probability of $100 \%$. As a consequence, benefits (avoided impacts from disasters) generally tend to be largely overestimated. Indeed, the literature reports study results of returns on DRR investment of 100: 1 or even more than 1000: 1, which need discussion and qualification (see Shreve and Kelman 2014).

This paper specifically considers the role of risk and examines the extent to which risk, as well as other best practice criteria, is taken care of in CBAs. The comprehensive review, conducted partially as background information for the UK Foresight Report on "Reducing Risks of Future Disasters" (Foresight 2012), as well as informing work of the Zurich Flood Resilience Alliance (see Mechler et al. 2014), addresses two key questions: What can be said about current and best practice regarding CBA for DRR including limitations and alternatives? And, what, if at all, can be said in terms of quantitative insight for informing policy and practice? As much as available, the study compares the documented evidence on the net benefits over a range of disaster reduction interventions, such as risk reduction, preparedness and risk financing. The review also critically discusses the applicability of cost-benefit analysis as well as other economic decision-supporting tools for assessing the efficiency of certain DRR interventions.

Overall, the assessment finds that the available evidence indeed suggests sizeable returns to disaster risk reduction and as a global estimate across interventions and hazards on average disaster risk reduction can be said to render benefits about four times the costs in terms of avoided and reduced losses. This global number, which for more frequent flood risk is higher than for rarer wind and earthquake risk, however, is based on overall about 40 studies conducted with most evidence reported for flood risk prevention and less so for other hazards. Moving beyond advocacy to implementation, economic efficiency assessment using cost-benefit analysis hold potential as a tool for prioritization in this context, yet, applicability may be limited and reserved for specific interventions. With a shifting emphasis from infrastructure-based options (hard resilience) to preparedness and systemic interventions (soft resilience), other tools such as cost-effectiveness analysis, multi-criteria analysis and robust decision-making approaches deserve more attention as well.

The discussion is organized as follows. Section 2 discusses the methodological background on CBA and its advantages and limitations for assessing disaster risk reduction. Section 3 presents key challenges for assessing costs and benefits of DRR, before the evidence found in the literature is presented in Sect. 4. Alternative methods for decisionmaking on costs and benefits of DRR are shortly introduced in the subsequent Sect. 5, which leads into the final discussion and conclusions with insights and implications garnered from the study.

\section{Methodological background: using cost-benefit analysis in disaster risk reduction}

\subsection{CBA as a decision-supporting tool for appraisal and evaluation}

CBA is a major decision-supporting tool used by governments to organize and calculate the societal costs and benefits, inherent trade-offs and economic efficiency of public policy, 
programme or project (Brent 1998). CBA has been widely used for many purposes and applications (see, e.g. Dasgupta and Pearce 1978; World Bank 2010). In a CBA, costs and benefits are compared under a common economic efficiency criterion in order to derive at a decision, for which in theory, all effects, costs and benefits, need to be monetized and aggregated.

CBA informs decisions regarding the project cycle. Projects such as investments into infrastructure are rooted in the context of general programming, i.e. setting principles and priorities for public investments and development cooperation. CBA can have an impact here, e.g. by broadly identifying the benefits of a planned set of interventions. The actual project planning starts with project identification and specification (preproject appraisal stage), where CBA can help with selecting potential projects. This leads to the next, the appraisal stage where project feasibility from different perspectives is checked. Alternative versions of a project are assessed under criteria of social, environmental and economic viability. In a fourth stage, the financing dimension of the project is determined which is followed by actual implementation. Finally, projects need to be evaluated ex-post after completion in order to determine actual benefits and whether the implemented project did meet the expectations. In addition to informing the project cycle, and important for this study, analyses may be conducted for informational and advocacy purposes, as a preproject appraisal, as a full-blown project appraisal or as ex-post evaluation (Brent 1998).

Purposes, resource and time commitments, and expertise required differ significantly for these products. Specific information requests will depend whether the client is a development bank or a municipality, between small-scale and large-scale investments, the planning of physical infrastructure or capacity building measures. At a very early stage, it is critical to achieve consensus among the interested and involved parties on the scope and breadth of the CBA to be undertaken. Table 1 provides a quick overview of a number of different CBA types, their purpose and resource and time commitment.

There are a number of key features common to any CBA, which are summarized in box 1 .

Three decision criteria are of major importance:

- Net present value (NPV) costs and benefits arising over time are discounted and the difference taken, which is the net discounted benefit in a given year. The sum of the net benefits is the NPV. A fixed discount rate is used to represent the opportunity costs of using the public funds for the given project. If the NPV is positive (benefits exceed costs), then a project is considered desirable.

- The $B / C$ ratio is a variant of the NPV. The benefits are divided by the costs. If the ratio is larger than 1, i.e. benefits exceed costs, a project adds value to society. Due to its intuition, the $\mathrm{B} / \mathrm{C}$ ratio is often used.

Table 1 Types of CBA, purposes and requirements

\begin{tabular}{lll}
\hline Product & Purpose & $\begin{array}{l}\text { Resource and time } \\
\text { commitment }\end{array}$ \\
\hline $\begin{array}{c}\text { Project } \\
\text { appraisal }\end{array}$ & $\begin{array}{c}\text { Ex-ante evaluation of accepting, modifying or rejecting project, } \\
\text { often by singling out most efficient measure among alternatives }\end{array}$ & +++ \\
$\begin{array}{c}\text { Evaluation } \\
\begin{array}{c}\text { Informational } \\
\text { study }\end{array}\end{array}$ & $\begin{array}{c}\text { Ex-post evaluation of project after completion } \\
\text { Provide a broad overview over costs and benefits }\end{array}$ & ++ \\
\hline
\end{tabular}


- Economic rate of return (ERR) Whereas the former two criteria use a fixed discount rate, this criterion calculates the interest rate internally, which is considered the return of the given project. A project is rated desirable if this ERR surpasses an average return on public capital determined beforehand.

These criteria, while building on the same principle of economic efficiency, offer different messages for different applications, e.g. the UK Government often uses the NPV rule, while the World Bank seems to prefer the ERR (HMT 2007; World Bank 2010). In many circumstances, the three methods are equivalent. Arguably, the $\mathrm{B} / \mathrm{C}$ ratio offers the highest intuitive appeal due to its relative metric (benefits per costs). As it has been used most frequently in the context of DRR, we also follow this tradition in this paper.

\subsection{CBA for assessing disaster risk reduction}

Economic analysis including CBA has been applied to assessing disaster risk reduction, and there is a specialized literature, including manuals, on using CBA and other appraisal methods in the context of natural disaster risk (see Benson and Twigg 2004; Benson and Twigg 2007; WMO 2015). CBA of DRR is nothing new, and in the USA, CBA of flood control projects was mandated by Congress under the 1936 Flood Control Act and has been used for evaluation of risk reduction projects since the 1950s. It has, in effect, been standard practice for more than half a century for organizations such as the US Federal Emergency Management Agency (FEMA) and the US Army Corps of Engineers. To many US (government) decision-makers, economic efficiency has been a very important aspect when devising disaster-related policies. It may even be said that in the USA, cost-benefit considerations have "at times dominated the policy debate on natural hazards", although it remains unclear to what extent decisions have been rigorously based on this tool (Burby 1991). The UK Government's Department for Environment, Food and Rural Affairs (DEFRA) and the World Bank also generally advocate the use of CBA for projects and policies including those related to disaster risk reduction (see, e.g. Ministry of Agriculture 2001; Penning-Rowsell et al. 1992). Lately, the development cooperation context has moved to the forefront due to interest by international financial institutions, donors and NGOs to gauge the economic efficiency of their interventions. As well, the recent context of austerity across many countries seems to call for specific consideration of the economic efficiency of projects including DRR. Overall, however, beyond rhetoric there is surprisingly little, robust evidence and reflection on the economic efficiency and benefits of preventive measures.

\subsubsection{Operationalizing CBA for DRR}

The following methodological steps can be identified for conducting CBA in this specific field of application (see Mechler 2005).

1. Risk analysis risk in terms of potential impacts without risk reduction has to be estimated. This entails estimating and combining hazard(s), exposure and vulnerability to an estimate of risk.

2. Identification of risk reduction measures and associated costs Potential risk reduction projects and alternatives can be identified and the costs measured.

3. Analysis of risk reduction As disaster risk is a downside risk, benefits are the risks avoided. The core benefits generated by investments in disaster risk reduction are reductions in future impacts and losses. 
4. Calculation of economic efficiency Finally, economic efficiency is assessed by comparing benefits and costs using different metrics.

Key difficulties in the context of DRR are related to measuring risk and estimating avoided or reduced risks due to interventions.

\subsubsection{Assessing risk and potential impacts}

Combining hazard, exposure and vulnerability leads to risk and the potential impacts a natural disaster may trigger. Risk is commonly defined as the probability of a certain event and associated impacts occurring. Potentially, there are a large number of impacts, in actual practice however, only a limited amount of those can and are usually assessed. Impacts can be distinguished around the three broad categories of social, economic and environmental effects, whether the effects are direct or indirect and whether they are originally indicated in monetary or non-monetary terms.

Social consequences may affect individuals or have a bearing on the societal level. Most relevant direct effects are the loss of life, people injured and affected, loss of important memorabilia, damage to cultural and heritage sites (in addition to the monetary loss). Main indirect social effects include increases in diseases (such as Cholera and Malaria), increases in stress symptoms or increased incidence of depression, disruption in school attendance, disruptions to the social fabric, disruption of living environments and the loss of social contacts and relationships post-event.

Economic impacts are usually grouped into three categories: direct, indirect and macroeconomic (also called secondary) effects (ECLAC 2003). These effects fall into stock and flow effects: direct economic damages are mostly the immediate damages or destruction to assets or "stocks", due to the event per se. A smaller portion of these damages results from the loss of already produced goods. The direct stock damages have indirect impacts on the "flow" of goods and services: indirect economic damages occur as a consequence of physical destruction affecting households and firms. Assessing the macroeconomic impacts involves estimating the aggregate impacts on economic variables like gross domestic product (GDP), consumption and inflation due to the effects of disasters, as well as due to the reallocation of government resources to relief and reconstruction efforts. As the macroeconomic effects reflect indirect effects as well as the relief and restoration effort, these effects cannot simply be added to the direct and indirect effects without causing duplication, as they are partially accounted for by those already (ECLAC 2003). ${ }^{1}$ It should be kept in mind that the social and environmental consequences also have economic repercussions. The reverse is also true since loss of business and livelihoods can affect human health and well-being.

Environmental impacts generally fall into two categories: impacts on the environment as a provider of assets that can be made use of (use values): e.g. water for consumption or irrigation purposes, soil for agricultural production. These impacts are or should be taken care of in the valuation of economic impacts. The second category relates to the

\footnotetext{
1 There is some discussion in the literature concerning potential double counting involved in adding direct and indirect impacts; this is due to the relation between direct impacts on assets (quantity at a single point in time) and indirect effects on flows (services/cash flows due to using the stocks over time). However, this argument assumes that all direct and indirect impacts can be assessed and the cost concept used for valuing asset losses is that of the book value (purchase value less depreciation), which are not realistic assumptions for disaster impact assessment. In applied impact assessments and CBAs deriving order of magnitude estimates and often using reconstruction values generally direct and indirect impacts are added up (see ECLAC 2003; GFDRR 2010).
} 
environment as creating non-use or amenity values. Effects on biodiversity and natural habitats fall into this category where there is not a direct, measurable benefit, but ethical or other reasons exist for protecting these assets and services.

\subsubsection{Cost and benefits of risk reduction options}

Based on the assessment of risk, potential risk reduction projects and alternatives can be identified. Projects incur costs and lead to benefits, which are derived by comparing the situation without implementation of a project. The costs in a CBA are the specific costs of conducting a project consisting of investment and maintenance costs. There are financial costs, the monetary amount that has to be spent for the project. However, of more interest are the so-called opportunity costs which are the benefits foregone from not being able to use these funds for other important objectives.

There is a wide spectrum of potential risk reduction, preparedness and risk-financing measures that can be taken in order to reduce or finance risk. Three types of measures can be identified, which have different effects: prevention reduces risk before events by modifying hazard, exposure and physical vulnerability. Preparedness reduces risk during events by modifying socio-economic vulnerability in terms of the response to disaster. Risk financing also modifies socio-economic vulnerability, but modifies risk only in terms of cutting out the variability of losses (statistically speaking the variance), not reducing risk overall (the expectation).

Key information on risk reduction measures required for quantitative cost-benefit analysis includes: (1) the exact type of the option under consideration, (2) its planned lifetime, (3) the costs such as investment costs and maintenance costs, (4) planned funding sources, (5) possibly additional benefits and impacts. This information can usually be established systematically; yet some uncertainty particularly with regard to the cost estimates usually remains as prices for material inputs and labour may be subject to fluctuations. Often, project appraisal documents make allowance for potential fluctuations by varying cost estimates by a certain percentage when appraising the costs.

\section{Review considerations: challenges associated with CBA for DRR}

While CBA can play a critical role in supporting decisions, its use and applicability are also constrained by important limitations. There are challenges, which are DRR specific and inherent to CBA. DRR-specific ones are (1) representing disaster risk, (2) assessing intangibles and indirect benefits from disaster risk reduction investments, (3) assessing portfolios of systemic interventions versus single interventions, (4) the role of spatial and temporal scales. There are also a number of general challenges inherent to CBA, which we discuss below. We now have a closer look at some of these challenges; then, for the review on CBA studies conducted, we will build on these challenges as a sort of best practice criteria.

\subsection{Challenges specific to disaster risk reduction}

\subsubsection{Representing disaster risk}

Disasters are low-probability, high-impact events and follow extreme event (so-called fattailed) distributions very different from normal distributions (see Hochrainer 2005). 
Ideally, such risk requires probabilistic analysis to adequately represent the potential for impacts as well as the benefits in terms of reduced impacts. A standard statistical concept for the probabilistic representation of natural disaster risk is the loss-exceedance curve, which indicates the probability of an event not exceeding (exceedance probability) a certain level of damages. The inverse of the exceedance probability is the recurrency period, i.e. an event with a recurrency of 100 years on average will occur only every 100 years. It has to be kept in mind that this is a standard statistical concept allowing to calculate events and its consequences in a probabilistic manner. However, a 100-year event could also occur twice or three times in a century, the probability of such occurrences however being very low. In order to avoid misinterpretation, the exceedance probability is often a better concept than the recurrency period. The area (the sum of all damages weighted by its probabilities) under the curve represents the expected annual damages, i.e. the annual amount of damages that can expected to occur over a longer time horizon. This concept helps translating infrequent events and damage values into an annual number that can be used for planning purposes. On the other hand, using the expectation of impacts only "smoothes" out over large events, such as a 100-year catastrophe. Ideally, whole distributions of risk are used in analysis of disaster risk. Due to methodological challenges, this is difficult and not often done in CBA assessments (or other analyses), as to be discussed further below.

Based on such a representation of risk, benefits of DRR can be assessed in terms of shifting the curve, and a downward shift would entail a reduction in potential impacts, thus producing benefits. This is shown in stylized fashion in Fig. 1.

Studying risk and benefits of reducing risk in a risk-based/probabilistic framework makes an important difference. Costs, which can be divided up into investment and maintenance costs, are deterministic, i.e. they arise for sure and often early on in the process. Benefits, created due to the savings in terms of avoided direct and indirect losses, on the other hand are probabilistic and arise only in case of events occurring. This is to say, that in most of the cases (years) where there are (fortunately) no disasters, no benefits arise from risk reduction projects. Thus, the viability of such a project is tied very closely to the expectation of the occurrence of disasters. As a consequence, for disasters occurring relatively rarely (e.g. earthquakes), benefits are smaller, and it may be more difficult to secure investment funds than for more frequent events such as flooding. If the probabilistic nature of the risks and benefits is not taken into account, benefits can be overestimated, which seems to occur frequently.

What is more, DRR options relate to risk as well and are differentially efficient for certain so-called layers of risk. In general, for the low-to-medium loss risk layers

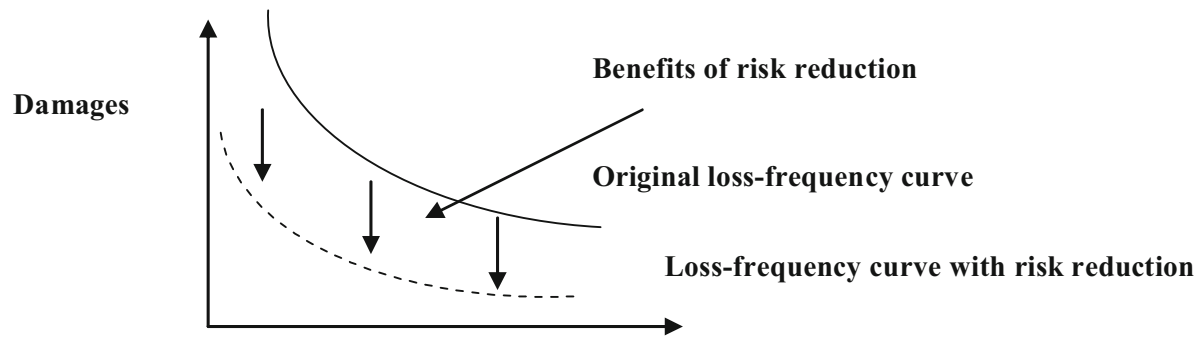

Exceedance probability

Fig. 1 Benefits of DRM in terms of shifting the loss-exceedance curve 
aggregating events that happen relatively frequently, prevention is likely more economically efficient in reducing burdens than insurance. The reason is that the costs of prevention often increase disproportionately with the severity of the consequences. Moreover, individuals and governments are generally better able to finance lower-consequence events from their own means, for instance, savings or calamity reserve funds, and including international assistance. The opposite is generally the case for costly risk-financing instruments, including insurance, catastrophe bonds and contingent credit arrangements. Catastrophe insurance premiums fluctuate widely and are often substantially higher than the pure risk premium (average expected loss), mainly because the insurer's cost of backup capital is reflected in the premium. For this reason, it may be advisable to use those instruments mainly for lower probability hazards that have debilitating consequences (catastrophes). Finally, most individuals and governments find it too costly to reduce risk or insure against very extreme risks occurring less frequently than, say, every 500 years, and for such infrequent risk, often little risk reduction planning occurs.

A truly risk-based analysis is thus of considerable importance in order to identify the most suitable options for certain portions of risk. Two reasons can be identified: disaster risk is probabilistic, and DRR options are efficient for certain layers of risk. While many events in life or the economy (sickness, stock market fluctuations, business default) are probabilistic, they often can be fairly well approximated by average values (means or the expectation) based on utilizing normal distributions unless the tails of the distributions are fat. The financial crisis has been an example, where there was recognition that there is need for considering the tails and going beyond the means. Clearly, for disaster risk, this is very important, as disasters by nature are "non-normal" and fat-tailed events.

A lack of data and associated uncertainties is often a key challenge for comprehensively assessing disaster risk and the benefits of DRR. Gaps and uncertainties are related to the following issues and elements of measuring risk.

- Hazard probability: Estimates can often be based on a limited number of data points only.

- Damage assessments: Data will not be available for all relevant direct and indirect effects, particularly so for the non-monetary effects. Estimates of damages from natural disasters often focus mainly on direct damages and loss of life, also due to the fact that there are difficulties in accounting for indirect and non-monetary damages. Yet, even figures on direct damages should be regarded as rough approximations since very few countries have systematic and reliable damage-reporting procedures.

- Assessing vulnerability: Vulnerability curves do often not exist, and this information has to be generated, which is often fraught with complications.

- Assessing exposure: The dynamics of population increase, urban expansion and increase in welfare should be accounted for.

- Identifying the benefits of risk reduction: Often it is difficult to accurately measure the effects and benefits of risk reduction measures.

- Discounting the future: The discount rate used reduces benefits over the lifetime of a project and thus has very important impact on the result.

Tackling these gaps and challenges, and creating the requisite data are associated with costs and considerable effort. ${ }^{2}$ The depth and robustness of assessments to be conducted

\footnotetext{
${ }^{2}$ Some databases put considerable effort in producing robust evidence, such as the Desinventar and EMDAT databases, as well as databases run by (re)insurers, which focus strongly on insured losses. See: online.desinventar.org/desinventar; www.emdat.be/Database/.
} 
thus depend upon the objectives of the respective CBA including the data at hand on hazard, vulnerability and exposure and finally impacts. Commonly, finding data on the elements of risk can be rather time-intensive and difficult. Particularly, information on the degree of damage due to a certain hazard (vulnerability) is usually not readily available. As a consequence, some CBA base their estimations on past impacts and sometimes try to update these to current conditions (see Mechler 2005).

Overall, natural disasters by definition are rare events, and thus in many cases, only a very limited number of values will be available. Thus, potential disaster impacts have to be understood as an approximation with the uncertainty around these calculations to be acknowledged.

\subsubsection{Challenges associated with assessing intangibles and indirect effects}

As stated, many of the costs and benefits from DRR can be of indirect and intangible nature, yet these can be difficult to identify and quantify for inclusion in a CBA. Quantitative disaster risk modelling has focussed on direct, tangible impacts, less so on the indirect and intangible effects. While techniques exist for quantifying avoided damages and valuing non-market benefits or costs, measurement challenges are large and, more fundamentally, techniques for valuation are often controversial.

In many cases, benefits of DRR come as reduced effects on household or country income and assets, yet there are no databases that systematically assess such effects as well as no standards for measuring these impacts. Non-market or intangible effects, such as loss of life or health impacts, are key for DRR, and while there are established techniques for valuing lives and injuries, e.g. as projections of lost future earnings, they all do not avoid value judgments and thus introduce substantial controversy (World Bank and UN 2010). The same holds true for softer environmental and social values, such as existence values for environmental goods as well as cohesion of a social group or community.

\subsubsection{Assessing portfolios of systemic interventions versus single interventions}

While assessments of the economic efficiency of DRR may focus on hazard and risk-specific interventions and their specific costs, it is well understood that DRR interventions often most usefully comprise a portfolio of interventions. What is more, these options may be integrated in broader developmental contexts and comprise investments into systemic interventions in sectors such as education, health or infrastructure, which may bring about large DRR-related benefits by building resilience. A focus on bolstering resilience in terms of maintaining key system functions in the face of adversity rather than reducing source-specific risk calls for a systemic understanding of the interrelationship of development, resilience and shocks. As discussed by Moench et al. (2007), the importance of resilience in social systems for reducing the impacts from extremes is of high relevance and has been well explained by Amartya Sen and others, e.g. for events such as droughts in India and China (see Sen 1999).

Such focus on system's thinking also invokes a distinction between hard and soft measures (see Moench et al. 2007). Hard resilience refers to the strengthening of structures and physical components of systems in order to brace against shocks imposed by extremes such as earthquakes, storms and floods. In contrast, soft resilience can be built by a set of less tangible and process-oriented measures as well as policy in order to robustly cope with events as they occur and minimize the adverse outcomes. To some extent, preparedness is part of soft resilience measures, yet structural measures can also exhibit some elements. It may be argued that the key distinction is learning to live with risk, rather than assuming 
risk can fully be eliminated. The role of inclusive and systemic approaches has been underlined recently with high confidence by the IPCC SREX report (IPCC 2012).

\subsection{Challenges inherent to CBA}

Some methodological challenges appear inherent to CBA more broadly.

\subsubsection{Limited role in informing decisions}

CBA cannot easily resolve conflicts and strong differences in value judgements that are often present in controversial projects and policies (e.g. nuclear power, biotechnology, but also flood management) (see also Wenz 1988; Gowdy 2007). The distribution of costs and benefits remains a key challenge. The general principle underlying CBA is the KaldorHicks criterion, which holds that those benefiting from a specific project or policy should potentially be able to compensate those that are disadvantaged by it (Dasgupta and Pearce 1978). Whether compensation is or can actually be done, however, is often ignored. Techniques for considering the distribution of costs and benefits exist, yet these are relatively complicated and have not found wide usage (Little and Mirlees 1990). CBA's ability to influence decision process and learning may be limited as a recent internal World Bank review shows. This review shows that the usage of cost-benefit analysis for informing decisions on projects has been declining. CBA seems often only to have been carried done after key decisions had been taken with the technical analysis often prepared by consultants, while senior project staff appeared to be more interested in aspects related to project safeguards, procurement and financial management. As another consequence, the potential of CBA to support learning during project appraisal and implementation has been considered very limited (World Bank 2010).

\subsubsection{Spatial and temporal scales}

A key uncertainty relates to the scale of analysis. While generally (with the exception of risk-financing options) DRR will be implemented on community and subnational levels, there is interest particularly by policymakers to generalize and work with national or global information. This holds true for CBA more widely. While originally strictly focused on a project level well specified in time and space, it has been used to inform larger-scale decisions (such as large-scale dam siting) and global climate change policy. As Gowdy suggests, however, as the remit of the analysis widens, it becomes less clear how the intervention produces costs and benefits, who benefits and who is disadvantaged, and what other external factors come in (Gowdy 2007).

One additional complication is the dynamic nature of (changing) hazard, exposure and vulnerability, and therefore risk. Unless future risk patterns are known, the costs and benefits of risk reduction cannot be accurately calculated. While this is important as risk prevention investments are associated with time horizon of 10, 20 or 30 years, the future patterns are however often unknown or very difficult to project forward.

\subsubsection{Discounting and choice of discount rate}

The choice of discount rates affects CBA results heavily, and, despite extensive research, there is debate. As one example, the Stern review on the economics of climate change 
leads to heavy debate due to the suggestion made to use low discount rates in order not to discount away future debilitating climate change, while mainstreaming economists suggested that market rates should be used instead (see Stern 2006). Although beyond this discussion, a similar argument could be made for catastrophic risk characterized by fat tails (i.e. events happening with low recurrency and leading to large impacts over future time periods), which would call for lower discount rates for DRR projects also. A number of studies take this point into account and conduct sensitivity analysis across discount rates.

\section{Reviewing and summarizing the evidence}

Table 2 in chronological order lists the 39 CBA studies on DRR interventions found in the literature in terms of location (country), hazards and types of DRR covered. Some of the studies contain multiple analyses leading to a total of 52 analyses reviewed. The table also scans the studies whether they address the five key challenges discussed above. Table A1 in the ESM reports more detail regarding benefits assessed and results arrived at. The review distinguishes between using CBA for (pre)project appraisals as well as expost evaluations of implemented projects. Some of the studies have focussed on the USA because the regulation there has required cost-benefit analysis to be conducted for each project receiving federal funding and documentation for the projects is readily accessible. Lately, the development cooperation context has moved to the forefront due to interest by international financial institutions, donors and NGOs to gauge the economic efficiency of their interventions, and a number of studies have been conducted for this context.

Unexpectedly, most interventions cover structural measures and here most prominently flood risk prevention. Yet, preparedness has increasingly been tackled. Risk-financing assessments have held some appeal, and some studies have aimed at assessing more comprehensive packages, such as flood risk prevention coupled with water management plans, or seismic retrofit integrated with risk financing (see Table 3).

\subsection{Summary of evidence}

Before discussing how the methodological challenges were addressed, we summarize the evidence found in terms of quantitative results. As analyses not providing a risk-based estimate of benefits and returns would tend to overestimate the economic efficiency, we only considered those analyses that are based on some estimate of risk (in terms of expectation and fuller probabilistic distributions), in total 39 out of the 52 analyses.

Overall, the evaluations reviewed here demonstrate that investing in DRR can pay in many contexts and for many interventions and hazards. The large majority of studies reported $\mathrm{B} / \mathrm{C}$ ratios larger than one, positive net present values and high economic rates of returns. A few studies also calculated that some interventions did not provide positive net values (Kull et al. 2008; Hochrainer-Stigler et al. 2010; ECA 2009; ERNAL 2010).

While it is very difficult to generalize, it may be said that a simple, global average of the $\mathrm{B} / \mathrm{C}$ ratios across interventions, regions and hazards may be around 4 with some important outliers. This statement is based on the review of all available estimates in the literature, as well as the MMC (2005) study (see Table 4). 
Table 2 Studies and coverage of key criteria

\begin{tabular}{|c|c|c|c|c|c|}
\hline Study-detail & Risk & Intangibles & $\begin{array}{l}\text { Indirect } \\
\text { effects }\end{array}$ & $\begin{array}{c}\text { Multiple } \\
\text { interventions }\end{array}$ & $\begin{array}{c}\text { Systemic } \\
\text { interventions }\end{array}$ \\
\hline \multicolumn{6}{|l|}{ EVALUATIONS (ex-post) } \\
\hline $\begin{array}{l}\text { Vermeiren and Stichter } \\
\text { (1998). Hurricane risk } \\
\text { prevention - Dominica and } \\
\text { Jamaica }\end{array}$ & D & & & & \\
\hline $\begin{array}{l}\text { FEMA (1998). Ex-post } \\
\text { evaluation of implemented } \\
\text { mitigation measures in the } \\
\text { paper and feed industries } \\
\text { in USA }\end{array}$ & D & & & & \\
\hline $\begin{array}{l}\text { BTRE (2002). Flood risk } \\
\text { management (Australia) }\end{array}$ & $\mathrm{R}$ & & & & \\
\hline $\begin{array}{l}\text { IFRC }(2002) \text {. Windstorm } \\
\text { risk prevention (Vietnam) }\end{array}$ & D & & & & \\
\hline $\begin{array}{l}\text { Venton \& Venton (2004) } \\
\text { Risk management of floods, } \\
\text { Bihar and Andhra Pradesh } \\
\text { (India) }\end{array}$ & D & & & & \\
\hline $\begin{array}{l}\text { MMC (2005). Review of } \\
\text { wide set of risk } \\
\text { management grant } \\
\text { programs (USA) }\end{array}$ & $\mathrm{R}$ & & & & \\
\hline $\begin{array}{l}\text { Ghesquiere et al. (2006). } \\
\text { EQ- risk management - } \\
\text { Colombia }\end{array}$ & $\mathrm{R}$ & & & & \\
\hline $\begin{array}{l}\text { Fuchs et al. (2006). } \\
\text { Avalanche risk reduction } \\
\text { strategies - Davos, } \\
\text { Switzerland }\end{array}$ & $\mathrm{R}$ & & & & \\
\hline $\begin{array}{l}\text { Mechler and Islam (2013). } \\
\text { Flood-proofing - } \\
\text { Bangladesh }\end{array}$ & $\mathrm{R}$ & & & & \\
\hline $\begin{array}{l}\text { Kull et al. (2013). } \\
\text { Flood risk prevention- } \\
\text { India }\end{array}$ & $\mathrm{R}$ & & & & \\
\hline $\begin{array}{l}\text { White\&Rorick (2010). } \\
\text { DRM flood interventions in } \\
\text { Kalali district, Nepal }\end{array}$ & $\mathrm{R}$ & & & & \\
\hline $\begin{array}{l}\text { IFRC (2011). } \\
\text { Coastal afforestation in } \\
\text { Vietnam }\end{array}$ & D & & & & \\
\hline $\begin{array}{l}\text { Kahn et al (2012). } \\
\text { Installation of boat winch } \\
\text { system, Vietnam }\end{array}$ & $\mathrm{R}$ & & & & \\
\hline $\begin{array}{l}\text { Eucker et al. (2012). } \\
\text { Community-based flood } \\
\text { risk management in } 4 \\
\text { districts in Bangladesh } \\
\end{array}$ & D & & & & \\
\hline \multicolumn{6}{|l|}{ APPRAISALS (ex-ante) } \\
\hline $\begin{array}{l}\text { Kramer (1995). } \\
\text { Windproofing banana trees, } \\
\text { St. Lucia }\end{array}$ & $\mathrm{R}$ & & & & \\
\hline $\begin{array}{l}\text { World Bank (1996). Flood } \\
\text { protection, Argentina }\end{array}$ & $\mathrm{R}$ & & & & \\
\hline $\begin{array}{l}\text { Dedeurwaerdere (1998). } \\
\text { Flood prevention measures } \\
\text {-Pampanga province, } \\
\text { Philippines }\end{array}$ & $\mathrm{R}$ & & & & \\
\hline
\end{tabular}


Table 2 continued

\begin{tabular}{|c|c|c|c|c|c|}
\hline Study-detail & Risk & Intangibles & $\begin{array}{l}\text { Indirect } \\
\text { effects }\end{array}$ & $\begin{array}{c}\text { Multiple } \\
\text { interventions }\end{array}$ & $\begin{array}{c}\text { Systemic } \\
\text { interventions }\end{array}$ \\
\hline $\begin{array}{l}\text { Smyth et al. (2004). Seismic } \\
\text { retrofit, Istanbul, Turkey }\end{array}$ & $\mathrm{R}$ & & & & \\
\hline $\begin{array}{l}\text { Mechler (2004). Sovereign } \\
\text { risk transfer, Honduras and } \\
\text { Argentina }\end{array}$ & $\mathrm{R}$ & & & & \\
\hline $\begin{array}{l}\text { Mechler (2005). Flood risk } \\
\text { prevention in Piura, Peru }\end{array}$ & $\mathrm{R}$ & & & & \\
\hline $\begin{array}{l}\text { Mechler (2005). Integrated } \\
\text { water management and } \\
\text { flood protection scheme in } \\
\text { Semarang, Indonesia }\end{array}$ & $\mathrm{R}$ & & & & \\
\hline $\begin{array}{l}\text { Kull et al. (2013). Flood risk } \\
\text { prevention in Uttar } \\
\text { Pradesh, India }\end{array}$ & $\mathrm{R}$ & & & & \\
\hline $\begin{array}{l}\text { Schroeter et al. (2008). } \\
\text { Early Warning in the } \\
\text { Traisen Basin, Lower } \\
\text { Austria }\end{array}$ & $\mathrm{R}$ & & & & \\
\hline $\begin{array}{l}\text { Schroeter et al. (2008). } \\
\text { Early Warning in the Besos } \\
\text { Basin in Catalunya, Spain }\end{array}$ & $\mathrm{R}$ & & & & \\
\hline $\begin{array}{l}\text { ECA (2009) and CCRIF } \\
(2010) . \\
\text { Climate risk adaptation cost } \\
\text { curves applied to national } \\
\text { and subnational level }\end{array}$ & $\mathrm{R}$ & & & & \\
\hline $\begin{array}{l}\text { Mora et al. (2009). } \\
\text { Retrofitting three groups of } \\
\text { public buildings in Bogota, } \\
\text { Colombia }\end{array}$ & $R$ & & & & \\
\hline $\begin{array}{l}\text { Mechler et al. (2009). } \\
\text { Integrated drought risk } \\
\text { management in Uttar } \\
\text { Pradesh. India }\end{array}$ & $\mathrm{R}$ & & & & \\
\hline $\begin{array}{l}\text { Subbiah et al. (2008). } \\
\text { Potential benefits of early } \\
\text { warning for hurricanes and } \\
\text { floods across a number of } \\
\text { case studies (Bangladesh, } \\
\text { Sri Lanka, Vietnam, } \\
\text { Thailand, Indonesia, India, } \\
\text { Philippines) }\end{array}$ & $R$ & & & & \\
\hline $\begin{array}{l}\text { Pinelli et al }(2009): \\
\text { Multiple hurricane } \\
\text { mitigation measures for } \\
\text { residential buildings in } \\
\text { Florida }\end{array}$ & $\mathrm{R}$ & & & & \\
\hline $\begin{array}{l}\text { Hochrainer-Stigler et al. } \\
\text { (2010), Comparison of } \\
\text { structural risk reduction } \\
\text { for hurricane, flood, and } \\
\text { earthquake hazards, St. } \\
\text { Lucia, Indonesia, Turkey, } \\
\text { and India }\end{array}$ & $R$ & & & & \\
\hline $\begin{array}{l}\text { Venton et al. (2010). Flood } \\
\text { prevention as part of safer } \\
\text { islands programme, } \\
\text { Maldives }\end{array}$ & $\mathrm{R}$ & & & & \\
\hline $\begin{array}{l}\text { ERN-AL (2010). } \\
\text { Retrofitting schools in Latin } \\
\text { America }\end{array}$ & $\mathrm{R}$ & & & & \\
\hline $\begin{array}{l}\text { Venton et al. (2012). } \\
\text { Building drought resilience } \\
\text { for pastoralists in Kenya } \\
\text { and Ethiopia }\end{array}$ & D & & & & \\
\hline $\begin{array}{l}\text { Kahn et al (2012). } \\
\text { Earthquake-safe } \\
\text { construction in Nepal }\end{array}$ & D & & & & \\
\hline $\begin{array}{l}\text { Zarine et al. (2015). } \\
\text { Building of tidal channel in } \\
\text { the Seychelles }\end{array}$ & $\mathrm{R}$ & & & & \\
\hline $\begin{array}{l}\text { Lazamanana et al. (2015). } \\
\text { Evaluating wind proofing } \\
\text { options in Madagascar }\end{array}$ & $\mathrm{R}$ & & & & \\
\hline $\begin{array}{l}\text { Leste-De Périndorge et al. } \\
\text { (2015). } \\
\text { Evaluating residential wind } \\
\text { proofing options in } \\
\text { Mauritius }\end{array}$ & $\mathrm{R}$ & & & & \\
\hline
\end{tabular}

Note: D: Deterministic analysis, R: Risk-based analysis 
Table 3 Consideration of different types of DRM in the analyses shading suggests the degree of evidence available from dark grey (relatively good) to light grey (little evidence)

\begin{tabular}{|l|l|l|}
\hline \multicolumn{3}{|c|}{ Disaster risk reduction } \\
\hline Prevention: Reducing risk & $\begin{array}{l}\text { Preparedness: Preparing for } \\
\text { events }\end{array}$ & $\begin{array}{l}\text { Risk financing: Transferring } \\
\text { and sharing risk }\end{array}$ \\
\hline $\begin{array}{l}\text { Physical flood risk } \\
\text { prevention (sometimes } \\
\text { coupled with water } \\
\text { management or } \\
\text { preparedness) }\end{array}$ & $\begin{array}{l}\text { Land use and evacuation } \\
\text { planning, training and capacity } \\
\text { building, shelters, emergency } \\
\text { kits, systemic interventions } \\
\text { (often assessed in combination) } \\
\text {-often for flood risk }\end{array}$ & $\begin{array}{l}\text { Sovereign risk financing and } \\
\text { microinsurance }\end{array}$ \\
\cline { 1 - 1 } $\begin{array}{l}\text { Seismic retrofit } \\
\text { Drought risk reduction in } \\
\text { agriculture and ecosystems }\end{array}$ & & \\
\cline { 1 - 1 } $\begin{array}{l}\text { Landslide and avalanche } \\
\text { risk management }\end{array}$ & & \\
\hline
\end{tabular}

Table 4 Summary results of average B/C ratios across studies

\begin{tabular}{llll}
\hline Hazard & $\begin{array}{l}\text { Review } \\
\text { Simple average } \\
\text { (number of studies) }\end{array}$ & $\begin{array}{l}\text { Review } \\
\text { Range of } \\
\text { estimates }\end{array}$ & $\begin{array}{l}\text { MMC (2005) } \\
\text { Average }\end{array}$ \\
\hline Flood (riverine and coastal) & $4.6(21)$ & $0.1-30$ & 5.0 \\
Wind (tropical and extratropical) & $2.6(7)$ & $0.05-50$ & 3.9 \\
Earthquake & $3.0(8)$ & $0.08-15.6$ & 1.5 \\
Drought & $2.2(1)$ & $1.3-2.2$ & na \\
Landslide and avalanche & $1.5(2)$ & $0.1-3.7$ & na \\
Overall & $3.7(39)$ & $0.08-50$ & 4.0 \\
\hline
\end{tabular}

Some studies comprise several analyses

Taking a simple average across all the analyses reviewed which consider disaster risk probabilistically (39 out of 52$)^{3}$ would lead to a B/C ratio of close to 4 (3.7), with average ranges for flood hazard close to 5 (4.6), wind hazards and earthquake close to 3 (2.6, resp., $3.0)$, and drought, and landslide and avalanche hazards around 2 (2.2, resp., 1.5 for 3 studies overall). Except for flood risk, these estimates rely on (very) few studies. Overall, these global results mirror results found in the MMC study with risk reduction $\mathrm{B} / \mathrm{C}$ ratios for flood risk reduction broadly similar, and for wind with lower values and for seismic hazard with higher estimates.

Comparing results across studies with very different methodological design is difficult, so it is useful to also resort to the findings of the MMC (2005) study, which took a consistent approach across all the hazards and cases analysed in an US context (see box 2). This large and comprehensive study was mandated by the US Senate to gauge the returns

\footnotetext{
${ }^{3}$ In total, of the studies reviewed, 24 estimates were finally considered based on whether B/C ratios were calculated and a risk-based approach was pursued. Two studies, MMC (2005) and Hochrainer-Stigler et al. (2010), offered a number of estimates.
} 
on the benefits of federal hazard mitigation grants. In retrospective analysis, investments in more than 5400 disaster risk reduction programs in the USA, including the retrofit of buildings against seismic, windstorm and flood risk, amounting overall to US $\$ 3.5$ billion, were estimated to have led to a discounted net present value of societal benefits of US\$14 billion overall. Thus, on average, every dollar spent by the US Federal Emergency Management Authority (FEMA) on risk reduction can be attributed with having provided the country with about $\$ 4$ in future benefits (MMC 2005).

When considering these broad summary estimates, there are a number of caveats to keep in mind. As the recent IPCC SREX report (IPCC 2012) concluded, "the applicability of rigorous CBA for evaluations of managing extreme events is limited based on limited evidence and medium agreement". ${ }^{4}$ The evidence base compiled here using estimates of $\mathrm{B} / \mathrm{C}$ ratios is limited with only 39 studies with most evidence reported for flood risk (21). Variation is considerable. A few studies, of which some do not use ranges for representing results, exhibit very high values of up to 17 and estimated ranges stretch from close to 0 to 50 for the $\mathrm{B} / \mathrm{C}$ ratio. Concerning applicability, while these numbers may have some appeal for policy suggesting DRR can indeed pay back, this does not mean that it automatically does. Whether DRR leads to positive and large returns depends, among others, on project design, context and choices regarding DRR interventions. In fact, a few evaluation studies show that some projects may not have been economically efficient or barely so. As well, methodological depth and choices vary significantly across studies. We now proceed to discussing these choices by way of the best practice criteria and challenges identified earlier.

\subsection{Coverage of key DRR-related challenges}

\subsubsection{Accounting for risk}

Few studies take a deterministic approach and compare effects of interventions between actual events only, and most analyses consider disaster risk probabilistically. Most of the studies assess risk in terms of expectation, and only a few studies take probabilistic analysis as far as relating $\mathrm{B} / \mathrm{C}$ ratios to layers of risk.

As an example of a full probabilistic analysis, the assessment by Ghesquiere et al. (2006), focussing on combining seismic risk prevention with risk financing in Colombia, shows the importance of risk-based analysis by pointing out that it may not be economically efficient to tackle the really frequent risk. The analysis finds that for the studied interventions, the project becomes the more economically efficient the higher the risk is (and less frequent in terms of exceedance probability). The output presented in Fig. 2 shows that when risk prevention is applied to the total portion of EQ risk, there is a probability of $32 \%$ that the project is economically efficient (vice versa with a $68 \%$ chance it is not). Also, with $22 \%$ probability benefits will exceed costs by a factor of 3 , and with $10 \%$ probability this ratio will be 10 . These findings highlight a need to better focus attention on reducing or transferring certain layers of risk, which is generally not done in studies.

Thus, in principle, it would be desirable if CBA analyses of DRR framed the analysis in terms of layers of risk, and in fact provide probabilistic output. The downside to this

\footnotetext{
4 This evidence and agreement statement follow the so-called IPCC uncertainty language guidance, see Mastrandrea et al (2010).
} 


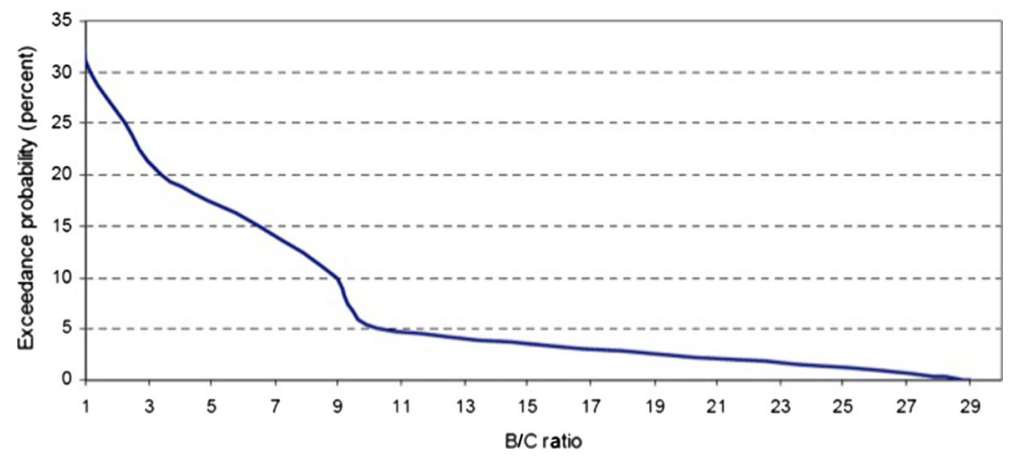

Fig. 2 Probabilistic B/C ratios for earthquake risk prevention in Colombia. Source: Ghesquiere et al. (2006)

suggestion is the higher complexity of the analysis as well as results, which also renders communication more difficult.

\subsubsection{Considering intangible impacts and benefits}

While it is possible to estimate values for many such elements, as the MMC (2005) study notes, the requisite data often are not available. In some cases, the data issue can be addressed by using benefit-transfer methods (essentially transferring the "values" identified in the literature to the specific case being analysed). Both the valuation process and the transfer between cases can, however, be controversial. As a result, non-monetized costs and benefits are often ignored.

The following example from the analysis of Venton and Venton (2004) is rather typical to what CBA analyses have covered. Information on physical (structural and infrastructural), human (people affected and killed) as well as economic (losses, relief and recovery spending) capital often is available and can be put into monetary values, if not counted in this dimension already.

Accounting for human impacts in CBA, however, poses key ethical issues. A contentious area of discussion concerns whether non-market values, such as impacts on human life of life, can and should be included into cost-benefit calculations. Many argue against measuring the "immeasurable" due to value judgments involved; others argue in favour of doing so, as else such values may be omitted from decision-making. Very few CBA studies in DRR have done so. One interesting example was carried out by Smyth et al. (2004), who probabilistically estimated the economic efficiency of different seismic retrofitting measures for one representative apartment building in Istanbul. Based on estimates of the expected direct damages and the costs of different retrofitting measures, the authors gauged the expected net present value of such measures. The analysis was conducted for different time horizons and with and without monetizing fatalities. For example, for the measure of bracing, the net present value was negative for all time horizons considered. This was similar for other measures as well. Only when including fatalities and a value of life (at US\$ 0.4 million/person), the project became cost-efficient for time horizons longer than 10 years (Fig. 2). This demonstrates the effects of including fatalities into estimates of losses, as well as considering a longer time horizon. The longer the time horizon the more likely the occurrence of disaster events in the modelling exercise will become generating benefits in terms of damages avoided (Fig. 3). 


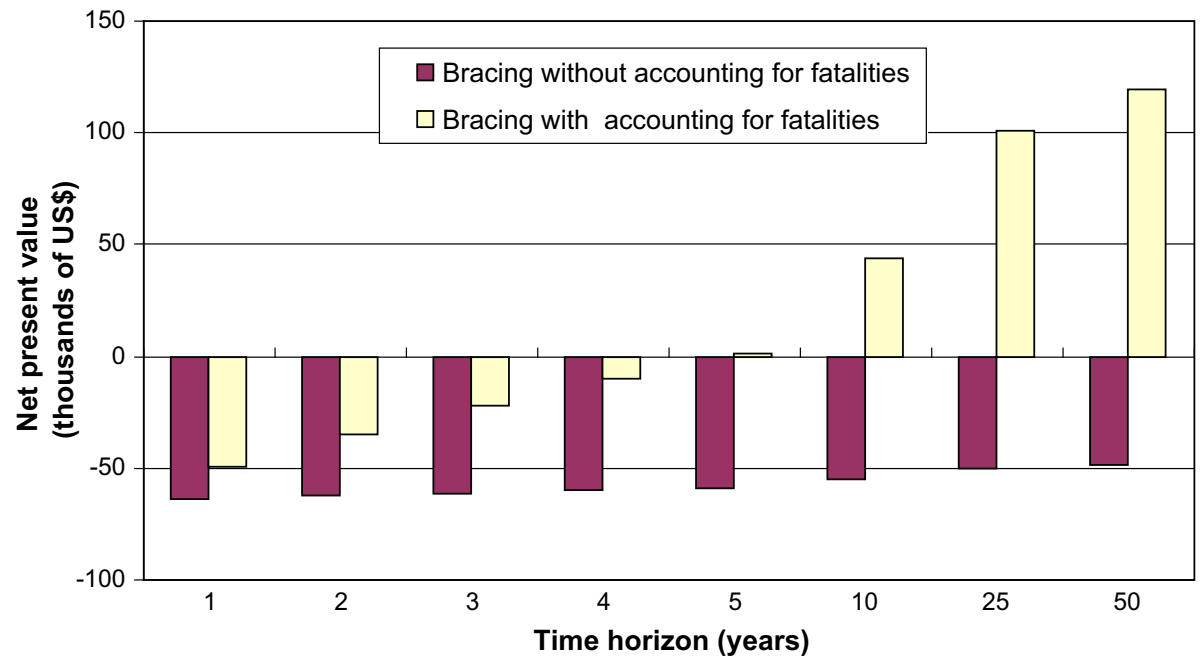

Fig. 3 Net present value for earthquake bracing an apartment building in Istanbul for different time horizons. Source: Smyth et al. (2004)

On the other hand, Kull et al. (2013) evaluated the historical performance of the embankment of the Rohini river in northern India since 1973 and found, when making the analysis more realistic by considering a host of intangible effects, that a project may eventually become inefficient. Traditional engineering analysis of infrastructure projects tends to ignore disbenefits and often does not capture all societal costs. Taking such an approach first based on official embankment costs and hydrologic engineering analysis at a discount rate of $10 \%$ (as standardly used by development banks), Kull et al. arrived at a benefit/cost ratio of about 4.6, indicating high economic efficiency. It might therefore be concluded that the embankments have been "worth it". When refining the analysis, however, the economic efficiency reduced greatly. By considering real land compensation costs, the benefit/cost ratio was about halved. Further adding to the analysis a better reflection of real embankment performance, i.e. insufficient maintenance (as also reflected in the costs) leading to failures, the benefit/cost ratio further reduced to about 1.6. When these disbenefits were explicitly taken into account, the embankments became economically inconclusive (benefit/cost ratio of 1.0). Considering that all disbenefit assumptions and computations were conservative, and reflecting on the many uncertainties within this probabilistic analysis, it thus cannot finally be concluded with confidence that the performance of embankments in these cases has been truly economically viable (see Fig. 4).

\subsubsection{Measuring indirect effects}

Most studies with a few exceptions (Venton and Venton 2004; Mechler 2004; MMC 2005; Mora et al. 2009; Mechler et al. 2008) considers as benefits (in terms of avoided losses) not the economic costs in terms of avoided changes in utility or consumption, as would be correct from a methodological perspective, but the financial, monetary costs. This has to do with the fact that the indirect effects are generally not factored into DRR analyses. As one example, Mechler et al. (2008) focussed their assessment entirely on the indirect effects, aiming at understanding what disaster risk means for the livelihoods of small-scale 


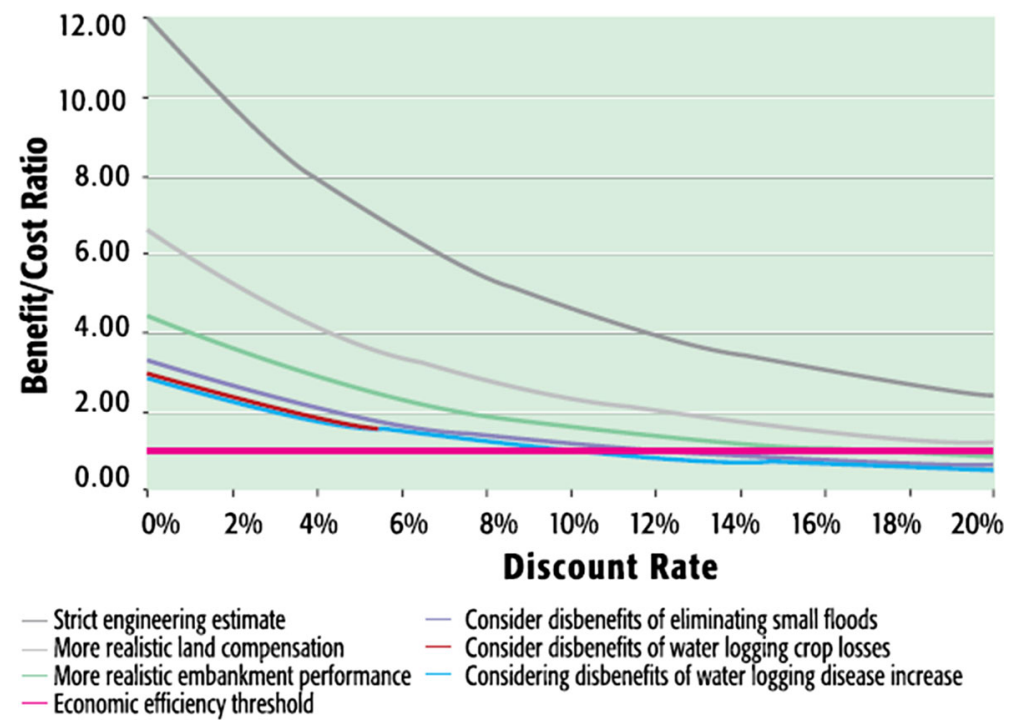

Fig. 4 Evaluation of the performance of embankments along the Rohini river basin in India. Source: Kull et al. (2008)

farmers. The study is based on, among other statistical sources, a survey with smallholders, which reported important large income losses (see chart 11). As such information is not regularly reported, this case study conducted extensive surveys to elicit such information, which then lead into the modelling analysis.

\subsubsection{Assessing multiple interventions}

Whereas earlier studies often focussed on single interventions, many analyses reviewed here studied multiple interventions for flood, seismic, drought and windstorm risk. As another example from Mechler et al. (2008), a combined intervention of risk reduction and risk financing was studied for helping drought-exposed farmers deal with extremes. While simple interventions showed positive B/Cs (with irrigation showing higher returns), a joint intervention produced even better results as in such an integrated approach benefits accrued both due to irrigation covering frequent drought events and due to insurance dealing with more extreme droughts (the $\mathrm{B} / \mathrm{C}$ ratios from the two interventions are not additive).

The most far-reaching study examining portfolios of options is documented by reports of the Economics of Climate Adaptation Working Group (ECA 2009; CCRIF 2010). Concentrating on national and subnational risk reduction options in the context of climate adaptation, the study went so far as to calculate adaptation cost curves in a set of countries. These curves organize a whole array of relevant risk reduction around their cost-benefit ratios. This very interesting effort thus tried to scope options for the whole risk a country or region is exposed to and organizes the options sequentially from very efficient to less efficient. Also, the study specifically estimated future risk by studying changes in hazard, exposure and vulnerability.

Yet, two points of criticism can be made. The first one relates to the concept of using cost curves for DRR (or adaptation). The cost curve concept arose from analyses of air pollution and climate mitigation, where end of pipe options for cleaning the air are 
assumed to be installed one after the other, for example, using different levels of car catalysts to clean exhaust. Adopting such a sequential approach seems questionable for DRR. While some options are indeed mutually exclusive across layers of risk, such as implementing flood embankments and purchasing flood insurance, others are not and may complement each other, such as building flood embankments or raising plinths of exposed houses. Therefore, the sequential implementation of options seems less applicable to DRR, where the portfolios of options are implemented jointly in order to reap the highest effect. The second point is more specific and relates to estimating risk and the robustness of estimates for a whole array of options and localities, which appears challenging given the comments of above. Although any estimate related to DRR will be subject to major uncertainties and thus it is good practice to identify results in terms of range, for matters of the cost curve concept, best estimates have to be used in order to avoid overlap and confusion as to which option to pick as one proceeds from highly efficient to less efficient (from left to right on chart 12); thus, ranges can neither be used nor displayed, which however may give rise to misinterpretation.

\subsubsection{Examining systemic approaches}

Interventions pertaining to systemic interventions (building community capacity overall through enhanced education and health interventions) were only assessed in 3 studies (Venton and Venton 2004; Eucker et al. 2012; Venton et al. 2012) of which the Venton et al. (2012) study does this exclusively. Yet, the robustness of the estimates compiled is not clear, and all three studies do not truly estimate risk based on probability, which renders estimates not robust. This may mean that the applicability of CBA as a tool to study such systemic interventions may be very limited.

\subsubsection{Uncertainty related to spatial and temporal resolution of the analysis}

As discussed, generalizing across spatial and temporal scales is not straightforward. As one example in favour of using localized information, for the analysis of flood risk and the efficiency of embankments in India, Kull et al. (2013) when following strictly an analysis that focuses on avoided flood losses only calculate high benefit/cost ratios. Yet, when also turning to potential disbenefits such large-scale infrastructure can bring about (waterlogging, health disamenities, etc.) and factoring in associated uncertainties with such estimates, it cannot reasonably be concluded that embankments historically performed economically satisfactorily. Generally, as scale and time horizon of projects and analysis, and thus uncertainties increase, it is important to question the usefulness and robustness of CBA.

As another example, CCRIF (2010) applied the cost curve concept to a number of Caribbean island cases including that of St Lucia. This application suggested that in order to deal with hurricane and flood-related damage in St Lucia options of coastal zoning, reef and mangrove revival, wind and inland zoning, coastal flood proofing and coastal drainage would be economically efficient. Yet, wind proofing of buildings would generally not be advisable from an economic perspective as the $\mathrm{B} / \mathrm{C}$ ratio was calculated at 0.25 to 0.2 . On the other hand, a study (Hochrainer-Stigler et al. 2010) done for the World Bank and UN report "Natural Hazards, Unnatural Disasters" (World Bank and UN 2010) on the benefits and costs of wind damage to housing structures in St. Lucia provided more detail and found that DRR can be efficient under certain circumstances. Representative houses at higher and lower risk locations were studied. While the ECA study suggested that wind proofing of 
residential homes in St Lucia was always inefficient, when zooming into spatial detail, Hochrainer-Stigler et al. showed that options for housing in specific location can be efficient and, as a best estimate, a B/C ratio of up to 2.7 was calculated.

This example demonstrates four issues: there are benefits to proceeding from general analysis to site-specific examination providing more detailed insights. It is crucially important to outline the many assumptions used in these studies and exert caution when using numbers to inform policy. Also, the example demonstrates that given the need to identify robust ranges of results it appears difficult to consistently carry through the cost curve framework requiring sequential implementation of options according to unambiguously identified economic efficiency information. Finally, as DRR measures often are embedded in local contexts with associated cost and risk profiles, upscaling results, e.g. for advocacy purposes, is associated with important robustness challenges.

\subsection{Tackling the challenge: alternative approaches for decision-making on risk reduction}

CBA is one tool for project appraisal and evaluation, which has received a lot of interest. But there are a number of alternative approaches for economic decision support, some of them lately receiving interest in the climate adaptation field. Cost-effectiveness analysis (CEA) is used to identify least-cost options to meet a certain, predefined target or policy objective. As the project costs are the key variable of consideration and subjected to finding cost-minimal solutions, CEA does not require the quantification of benefits (which are fixed/decided beforehand as a target, such as reducing disaster fatalities and losses to a certain level) (see World Bank 2004).

Another decision-supporting approach is multi-criteria analysis (MCA). With an emphasis on low cost (not least cost as in CEA, and optimal cost in relation to benefits as in CBA), the methodology is organized around objectives, criteria and indicators. Criteria are attributes, which can be used to compare the performance of different (policy) options in achieving one's stated objectives (economic, social, environmental and fiscal criteria). As another methodological element, indicators are verifiable measures, which can be used to monitor changes over time and space in the behaviour of the attributes mentioned above. They can be expressed in quantitative (monetary or not) or qualitative terms. A very limited number of studies have used MCA tools in the context of managing extremes, such as Debels et al. (2009) for a quick evaluation of climate adaptation practices in terms in Latin America, and De Bruin et al. (2009), who use a hybrid approach based on qualitative and quantitative assessments of adaptation options for flood risk in the Netherlands. Lately, in the context of climate adaptation, so-called robust decision-supporting approaches have been receiving increasing emphasis. This set of options comprising quantitative as well as qualitative approaches focuses away from optimal decisions (such as supported with CBA) and identifying options with minimum regret, i.e. minimal losses in benefits in a chosen strategy where some parameters have been uncertain. A key aspect is the notion of iteration and repeated analysis with modified assumptions and scenarios. This may mean running many simulations for tracing out uncertainty across key variables. Methods are however rather complex and often require advanced statistical and mathematical expertise (see Lempert and Collins 2007; Ranger et al. 2010). 


\section{Discussion and conclusions: going forward with and beyond CBA in a changing climatic and socio-economic context}

There is a lot of rhetoric regarding the large economic returns created by disaster risk management. Cost-benefit analysis (CBA) is a major tool that can provide such quantitative information informing the prioritization of risk management. This decision-supporting technique has been used over the years for this purpose, yet there is surprisingly little robust evidence on the efficiency and benefits of preventive measures, although lately more and different projects and options have been being studied.

This review has argued that for the limited evidence reported in the literature the economic case for DRR across a range of hazards is strong, and that the benefits of investing in DRR outweigh the costs of doing so on average, by about four times the cost in terms of avoided and reduced losses. At the same time, import caveats remain. This global number, potentially useful for broad advocacy purposes, is based on overall about 40 analyses with most evidence reported for flood risk prevention and less so for other hazards. Moving beyond advocacy to practice, it is clear that any estimates are casespecific; in fact, a few studies also found that under certain circumstances, DRR options may not always be economically efficient, which can also be interpreted as suggesting that studies are becoming more realistic, as in practice projects do not always play out as planned and some may actually not be beneficial at all depending on design and context. The brunt of the reported evidence exists for flood risk prevention, sometimes coupled with water management and preparedness. Less is known about earthquake risk reduction, drought and hurricane risk management, disaster preparedness and risk financing.

The robustness of these estimates is limited. There are a limited number of studies on hazards other than floods, challenges with monetizing benefits are to be reckoned with, and pursuing a risk-based analysis is associated with important methodological and data challenges. Overall, this review, in line with the recent IPCC SREX report, concludes that "the applicability of CBA for DRR is limited given limited evidence and medium agreement across the studies reported in the literature".IPCC (2012).

\subsection{Going forward with CBA}

There is a role for CBA in providing support for prioritizing DRR projects; however, context is important and a number of challenges inherent to CBA and specific to the application in DRR need to be acknowledged. It appears that CBA is well suited for projects, where benefits can be rather well identified in monetary terms. This is generally the case for hard resilience type of options (such as flood risk prevention), where benefits accrue in terms of avoided and reduced losses to structures such as flood embankments. Consequently, substantial evidence exists here. Softer and more systemic interventions are more difficult to assess comprehensively, and it is not clear that CBA is the best tool to gauge economic efficiency for this type of DRR interventions. Some of challenges associated with DRR can be overcome, and best practice guidance by way of manuals and reports exists laying out methodologies, which can be applied (Penning-Rowsell et al. 1992; Benson and Twigg 2004; Mechler 2005).

As the review suggests, there has been important progress in tackling some methodological difficulties in current practice. Estimating risk is one of those, and more recently, more and more studies have become available using a risk-based approach, where potential losses are associated with probability and return periods. The discussion has focussed on 
so-called frequentist techniques, i.e. techniques for eliciting values when risks and distributions can be observed and quantified. Many times this is difficult, and risk is often dynamic. In principle, Bayesian approaches can be used that allow the updating of distributions (e.g. Graf et al. 2009). Furthermore, real option techniques should be mentioned that consider dynamics in risk (and thus benefits) as well as suggest flexibility in terms of an option value to modify projects. Whereas in standard CBA (trends in) risks and benefits are generally considered rather constant over time, real options allow for uncertainty and future changes. Such techniques focus on finding optimal timing and amounts of investments today and in the future (Ranger et al. 2010).

Yet, overall some challenges are inherent to CBA more broadly and need proper attention. As is generally known in the practice of CBA throughout (and discussed in detail here), results can be highly sensitive to assumptions, omissions and issues studied. These challenges of CBA are well known to decision-makers throughout, yet field practitioners working on DRR may be less versed in the nuances and necessary assumptions involved in deriving costs and benefits for DRR projects. Care should thus be exercised when interpreting and communicating CBA and its results for informing decisions. As a consequence, it would be good to make it standard practice, and actually often has been made already so particularly for the DRR context, to properly identify the key assumptions taken, and report results informed by uncertainty and sensitivity analysis, for example, in terms of ranges related to high, low and best estimates.

\subsection{Going beyond CBA}

There are a number of methodological challenges that merit looking beyond CBA, particularly what concerns CBA's inability to value softer and intangible benefits comprehensively as well as to examine systemic interventions. This set of challenges closely has to do with underlying values and preferences. CBA generally cannot resolve strong differences in value judgments that are often present in controversial projects involving space and time. This may be important when it comes to large-scale structural interventions, such as building embankments, but also for identifying systemic interventions, which build resilience across many sectors. As analysis has shown, while there are many benefits to "hard" infrastructure-type measures and these are very appealing to policymakers with visible effects in case of large-scale events, there can also be important disbenefits such as waterlogging in annual, higher frequency flooding, which can be important and eventually may lead to rendering projects inefficient. As DRR projects are increasingly looking at multiple and systemic interventions, these challenges are increasingly important, and thus unlikely to quickly go away.

It is thus useful and important to look for other decision-supporting tools, established and new. Opportunities exist for going beyond CBA and its need to strictly monetize and aggregate costs and benefits, and using more holistic methods, such as multi-criteria analysis or robust decision-making approaches. There are trade-offs, though. Multi-criteria is a broader framework, and probably more useful as a process-based approach, rather than providing advocacy. Robust approaches are technically more sophisticated and demand more analytical skills. Particularly, evaluations using robustness as a criterion and focussing on so-called low regrets measures seem very useful, and the climate adaptation context and practice field are embracing this framing and approach. This implies a stronger focus on the uncertainty of risks and options for risk management as well as a focus on the overlap with benefits associated with today's development decisions, and the relaxation of the strict decision criterion that benefits have to exceed costs. This may be a way forward, 
as it provides useful entry points for crosscutting action involving DRR, climate adaptation and development interventions more generally. While formalizations exit, there has not been a large amount of application (mostly in the field of climate adaptation) owing to the fact that application requires advanced statistical and mathematical skills and results cannot as easily and intuitively be summarized such as using $\mathrm{B} / \mathrm{C}$ ratios.

CBA will continue to offer appeal to decision-makers and practitioners due to its intuitive ease, and in fact, many analysts see its main strength in that it is an explicit and rigorous accounting tool for measuring those costs and benefits, gains and losses, that can be effectively monetized, and in so doing, for making decisions more transparent. Yet, to provide qualification, CBA appears to not often have been truly used to prioritize implementation of options. Coupled with important technical challenges related to conducting a full-blown analysis, particularly in a data poor environment, this may very well mean that using CBA in informing project investment decisions may be indeed more related to process than outcome. Thus, CBA assessments for examining options to reduce, prepare for and finance disaster risk, may be used as a heuristic decision-supporting tool helping practitioners and policymakers to comprehensively categorize, organize, assess and present information on the various costs and benefits of specific projects, policies and strategies. Such crucial input on the economic efficiency of interventions coupled with information on values and preferences, potentially organized around iterative rounds of decision-making, instead of directly leading to the prioritization of any intervention, would seem to help inform and take forward the decision process on DRR more broadly.

Acknowledgments Open access funding provided by International Institute for Applied Systems Analysis (IIASA). Support by Zurich Insurance for work conducted as part of the Zurich Flood Resilience Alliance is gratefully acknowledged. As well, support by the UK Government Science Office is gratefully acknowledged as well. The author expresses his gratitude to Rory Mody, Mark Galtrey and Daniel Leary of the Foresight study team as well as two anonymous referees for excellent comments. Data compilation support by Callahan Egan is recognized as well.

Open Access This article is distributed under the terms of the Creative Commons Attribution 4.0 International License (http://creativecommons.org/licenses/by/4.0/), which permits unrestricted use, distribution, and reproduction in any medium, provided you give appropriate credit to the original author(s) and the source, provide a link to the Creative Commons license, and indicate if changes were made.

\section{References}

Benson C, Twigg J (2004) Measuring mitigation: methodologies for assessing natural hazard risks and the net benefits of mitigation-a scoping study. International Federation of Red Cross and Red Crescent Societies (IFRC); ProVention Consortium, Geneva

Benson C, Twigg J (2007) Tools for mainstreaming disaster risk reduction: guidance notes for development organisations. International Federation of Red Cross and Red Crescent Societies/the ProVention Consortium, ProVention Consortium Secretariat, Geneva

Brent RJ (1998) Cost-benefit analysis for developing countries. Edward Elgar, Cheltenham

BTRE (2002) Benefits of flood mitigation in Australia. Bureau of Transport and Regional Economics, Commonwealth of Australia, Canberra

Burby R (ed) (1991) Sharing environmental risks. How to control Governments' Losses in Natural Disasters. Westview Press, Boulder

CCRIF-Caribbean Catastrophe Risk Insurance Facility (2010) Enhancing the climate risk and adaptation fact base for the Caribbean. An informational brochure highlighting the preliminary results of the ECA Study. CCRIF, Georgetown

Dasgupta AK, Pearce DW (1978) Cost-benefit analysis: theory and practice. Macmillan, London

De Bruin K, Dellink RB, Ruijs A, Bolwidt L, van Buuren A, Graveland J, de Groot RS, Kuikman PJ, Reinhard S, Roetter RP, Tassone VC, Verhagen A, van Ierland EC (2009) Adapting to climate change 
in The Netherlands: an inventory of climate adaptation options and ranking of alternatives. Clim Change 95:23-45

Debels P, Szlafsztein C, Aldunce P, Neri C, Carvajal Y, Quintero-Angel M, Celis A, Bezanilla A, Martinez D (2009) IUPA: a tool for the evaluation of the general usefulness of practices for adaptation to climate change and variability. Nat Hazards 50(2):211-233

Dedeuwaerdere A (1998) Cost-benefit analysis for natural disaster management: a case study in the Philippines. Center for Research on the Epidemiology of Disasters (CRED), Brussels

ECA-Economics of Climate Adaptation Working Group (2009) Shaping climate-resilient development: a framework for decision-making study. Report of the Economics of Climate Adaptation Working Group, New York

ECLAC (2003) Handbook for estimating the socio-economic and environmental effects of disasters. ECLAC, Mexico City

ERN-AL (2010) Seismic risk assessment of schools in the Andean region in South America and Central America. Consortium Evaluación de Riesgos Naturales-América Latina, Bogotá

Eucker D, Bolte P, Rahmadana MF (2012) The long road to resilience. Impact and cost-benefit analysis of community-based disaster risk reduction in Bangladesh. Bangladesh Red Crescent Society (BDRCS), Dhaka

FEMA (1998) Protecting business operations: second report on costs and benefits of natural hazard mitigation. Federal Emergency Management Agency, Washington, DC

Foresight Reducing Risks of Future Disasters: Priorities for Decision Makers (2012) Final project report. The Government Office for Science, London

Fuchs S et al (2006) Avalanche hazard mitigation strategies assessed by cost effectiveness analysis and cost benefit analyses—evidence from Davos, Switzerland. Nat Hazards. doi:10.1007/s11069-006-9031-z

GFDRR-Global Facility for Disaster Risk Reduction (2010) Guidance note for conducting damage and loss assessments after disasters. GFDRR, Washington, DC

Ghesquiere F, Jamin L, Mahul O (2006) Earthquake vulnerability reduction program in Colombia. A probabilistic cost-benefit analysis. World Bank policy research, working paper 3939

Gowdy J (2007) Toward an experimental foundation for benefit-cost analysis. Ecol Econ 63:649-655

Graf M, Nishijima K, Faber M (2009) Bayesian updating in natural hazard risk assessment. Aust J Struct Eng 9(1):35-44

Hawley K, Moench M, Sabbag L (2012) Understanding the economics of flood risk reduction: a preliminary analysis. Institute for Social and Environmental Transition-International, Boulder

HMT (2007) The Green book. Appraisal and evaluation in central government treasury guidance. Her Majesty's Treasury. TSO, London

Hochrainer S (2005) Macroeconomic risk management against natural disasters. Deutscher UniversitaetsVerlag, Wiesbaden

Hochrainer-Stigler S, Kunreuther H, Linnerooth-Bayer J, Mechler R, Michel-Kerjan E, Muir-Wood R, Ranger N, Vaziri P, Young M (2010) The costs and benefits of reducing risk from natural hazards to residential structures in developing countries. Working paper \# 2010-12-01. The Wharton School, University of Pennsylvania, Philadelphia

IFRC (2002) World disasters report 2002. International Federation of the Red Cross and Red Crescent Societies, Geneva

IFRC (2011) Breaking the waves: impact analysis of coastal afforestation for disaster risk reduction in Viet Nam. IFRC (International Federation of Red Cross and Red Crescent Societies), Geneva

IPCC (2012) Managing the risks of extreme events and disasters to advance climate change adaptation. In: Field CB, Barros V, Stocker TF, Qin D, Dokken DJ, Ebi KL, Mastrandrea MD, Mach KJ, Plattner G-K, Allen SK, Tignor M, Midgley PM (eds). Cambridge University Press, Cambridge

Khan F, Moench M, Reed SO, Dixit A, Shrestha S, Dixit K (2012) Understanding the costs and benefits of disaster risk reduction under changing climate conditions: case study results and underlying principles. Institute for Social and Environmental Transition-International, Bangkok

Kramer RA (1995) Advantages and limitations of benefit-cost analysis for evaluating investments in natural disaster mitigation. In: Munasinghe M, Clarke C (eds) Disaster prevention for sustainable development: economic and policy issues. World Bank, Washington, DC

Kull D, Singh P, Chopde (2008) From risk to resilience. Evaluating costs and benefits of flood reduction under changing climatic conditions: case of the Rohini River Basin, India. Risk to resilience working paper 5. Moench M, Caspari E, Pokhrel A (eds) ISET, ISET-Nepal and ProVention, Kathmandu, Nepal. Provention Consortium, Geneva

Kull D, Mechler R, Hochrainer-Stigler S (2013) Probabilistic cost-benefit analysis of disaster risk management in a development context. Disasters 37(3):374-400 
Lazamanana AP, Ishigaki K, Moriniere L, Egan C, Mochizuki J, Hochrainer-Stigler S, Mechler R, Williges K (2015) UNISDR working papers on public investment planning and financing strategy for disaster risk reduction: review of Madagascar. UNISDR, Geneva

Lempert R, Collins M (2007) Managing the risk of uncertain threshold responses: comparison of robust, optimum, and precautionary approaches. Risk Anal 27:1009-1026

Leste-De Périndorge P, Ishigaki K, Moriniere L, Egan C, Mochizuki J, Hochrainer-Stigler S, Mechler R, Williges K (2015) UNISDR working papers on public investment planning and financing strategy for disaster risk reduction: review of Mauritius. UNISDR, Geneva

Little I, Mirlees J (1990) Project appraisal and planning twenty years on. In: Fischer S, de Tray D, Shah S (eds) Proceedings of the World Bank annual conference on development economics. The World Bank, Washington, DC

Mastrandrea MD, Field CB, Stocker TF, Edenhofer O, Ebi KL, Frame DJ, Held H, Kriegler E, Mach KJ, Matschoss PR, Plattner G-K, Yohe GW, Zwiers FW (2010). Guidance note for lead authors of the IPCC fifth assessment. Report on consistent treatment of uncertainties. Intergovernmental Panel on Climate Change (IPCC), Geneva, Switzerland, www.ipcc.ch

Mechler R (2004) Natural disaster risk management and financing disaster losses in developing countries. Verlag für Versicherungswirtschaft, Karlsruhe

Mechler R (2005) Cost-benefit analysis of natural disaster risk management in developing countries. Deutsche Gesellschaft für Technische Zusammenarbeit (GTZ). Arbeitskonzept, Eschborn

Mechler R (2010) Multi-criteria analysis for climate change: developing guidance for sound climate policy planning. Theme: managing extreme weather events. Contribution to the UNEP project MCA4 climate. Final report

Mechler R, Islam N (2013). Cost benefit analysis of disaster risk management and climate adaptation in Bangladesh. In: Guha-Sapir D, Santos I (eds) The economic impacts of natural disasters. Assessing the costs of prevention, mitigation and adaptation. Cambridge University, pp 80-106

Mechler R, Hochrainer S, Kull D, Chopre S, Singh P, Opitz-Stapleton S, Wajih S (2008) Uttar Pradesh drought cost-benefit analysis. Risk to resilience working paper 4. In: Moench M, Caspari E, Pokhrel A (eds) ISET, ISET-Nepal and ProVention, Kathmandu, Nepal. Provention Consortium, Geneva

Mechler R, Czajkowski J, Kunreuther H, Michel-Kerjan E, Botzen W, Keating A, McQuistan C, Cooper N, O'Donnell I (2014) Making communities more flood resilient: the role of cost benefit analysis and other decision-support tools in disaster risk reduction. White paper, Zurich Flood Resilience Alliance. http://opim.wharton.upenn.edu/risk/library/ZAlliance-decisiontools-WP.pdf

Ministry of Agriculture (2001) Flood and coastal defence project appraisal guidance. Overview. Ministry of Agriculture, London

MMC (2005) Natural hazard mitigation saves: an independent study to assess the future savings from mitigation activities. Volume 2-study documentation. Multihazard Mitigation Council, Washington, DC

Moench M, Mechler R, Stapelton S (2007) The costs and benefits of disaster risk management and cost benefit analysis. Background paper prepared for UNISDR High level Platform on Disaster Risk Reduction. Geneva, June 4-7, 2007

Mora MG, Ordaz M, Yamin LE, Cardona OD (2009) Relaciones beneficio costo probabilistas del refuerzo sísmico de edificios. Memorias del IV Congreso Nacional de Ingeniería Sísmica. Pereira, Colombia mayo 13,14 y 15 de 2009

Penning-Rowsell E, Green C, Thompson P, Coker A, Tunstall S, Richards C, Parker D (1992) The economics of coastal management-a manual of benefit assessment techniques (The Yellow Manual). Belhaven/Wileys, London

Pinelli J, Torkian B, Gurley K, Submaranian C, Hamid S (2009) Cost effectiveness of hurricane mitigation measures for residential buildings. In: 11th Americas conference on wind engineering, San Juan, Puerto Rico, June 22-26, 2009

Ranger N, Millner A, Dietz S, Fankhauser S, Lopez A, Ruta G (2010) Adaptation in the UK: a decision making process. Grantham/CCCEP Policy Brief funded by the Adaptation Sub-Committee

Schroeter K, Velasco C, Torres D, Nachtnebel H-P, Kahl B, Beyene M, Rubin C, Gocht M (2008) Effectiveness and efficiency of early warning systems for flash-floods. CRUE Research Report No I-5

Sen A (1999) Poverty and famines. Oxford University Press, Delhi

Shreve CM, Kelman I (2014) Does mitigation save? Reviewing cost-benefit analyses of disaster risk reduction. Int J Disaster Risk Reduct 10(Part A):213-235

Smyth AW, Altay G, Deodatis G, Erdik M, Franco G, Gülkan P, Kunreuther H, Luş H, Mete E, Seeber N, Yüzügüllü Ö (2004) Probabilistic benefit-cost analysis for earthquake damage mitigation: evaluating measures for apartment houses in Turkey. Earthq Spectra 20:171-203

Stern N (2006) The economics of climate change: the stern review. Cabinet Office-HM Treasury, London 
Subbiah A (2008) Assessment of the economics of early warning systems for disaster risk reduction. Background paper for World Bank-UN Project on the Economics of Disaster Risk Reduction. World Bank

UN (2105) Sendai framework for disaster risk reduction 2015-2030. A/CONF.224/CRP.1, 18 March, 2015

Venton C, Venton P (2004) Disaster preparedness programmes in India: a cost benefit analysis. Humanitarian Practice Network. ODI, London

Venton C, Venton P, Shaig A (2010) Cost benefit study of disaster risk mitigation measures in Three Island in the Maldives. United Nations Development Programme, Male

Venton C, Fitzgibbon C, Shitarek T, Coulter L, Dooley O (2012) The economics of early response and disaster resilience: lessons from Kenya and Ethiopia. Final report

Vermeiren J, Stichter S et al (1998) Costs and benefits of hazard mitigation for building and infrastructure development: a case study in small island developing states. In: Conference of the international emergency management society

Wenz P (1988) Environmental justice. State University of New York Press, New York

White B, Rorick M (2010) Cost-benefit analysis for community-based disaster risk reduction in Kailali, Nepal. Mercy Corps, Nepal

WMO-World Meteorological Organization (2015) Valuing weather and climate: economic assessment of meteorological and hydrological services. WMO, Geneva

World Bank (1996) Argentina flood protection project. Staff appraisal report 15354. World Bank, Washington, DC

World Bank (2004) Project appraisal document on a proposed loan in the amount of US\$150 million and a grant from the global environment facility in the amount of US\$7 million for Government of Romania for a hazard risk mitigation and emergency preparedness project. Report No: 28217 RO. World Bank, Environmentally and Socially Sustainable Development Unit, Europe and Central Asia Region, Washington, DC

World Bank (2010) Cost benefit analysis in world bank projects. The International Bank for Reconstruction and Development/The World Bank, Washington, DC

World Bank and United Nations (2010) Natural hazards, unnatural disasters: the economics of effective prevention. World Bank, Washington, DC

Zarine W, Ishigaki K, Moriniere L, Egan C, Mochizuki J, Hochrainer-Stigler S, Mechler R, Williges K (2015) UNISDR working papers on public investment planning and financing strategy for disaster risk reduction: review of Seychelles. UNISDR, Geneva 